\title{
An Empirical Study of Factors that Influence the Extent of Deployment of Electronic Commerce for Small- and Medium- sized Enterprises in Australia
}

\author{
Sandy Chong ${ }^{1}$ \\ ${ }^{1}$ Curtin University of Technology, Curtin Business School, Sandy.Chong@cbs.curtin.edu.au
}

Received 28 May 2006; accepted 27 July 2006

\begin{abstract}
The purpose of this paper is to present the perceptions and experiences of Electronic Commerce (EC) implementation in Australia. The study is investigated from the perspective of Small- and Medium-sized Enterprises (SMEs) and the framework of implementation is represented by the extent of deployment. Based on the sample of about 115 small businesses in Australia, this paper uses regression modelling to explore and establish the factors that are related to the extent of deployment in EC. A multiple regression analysis shows that seven factors: perceived relative advantage, trialability, observability, variety of information sources, communication amount, competitive pressure, and non-trading institutional influences, significantly influence the extent of EC deployment by SMEs in Australia. The results and interpretations have some implications for managers in determining the appropriateness of deploying EC strategies to achieve profitability and operational efficiency.
\end{abstract}

Key words: Business-to-Business Electronic Commerce, Adoption and Implementation Success, Extent of Deployment, Internet, Small- and Medium-sized Enterprises. 


\section{Introduction}

Electronic Commerce (EC) has emerged as a whole business strategy that enables organisations to improve business processes and communication, both within the organisation and with trading partners. Despite the economic downturn and the burst of the "dot-com" bubble, EC is expected to continue its significant growth. In the US alone, the second decade of EC would boost online sales from \$172 billion in 2005 to \$329 billion in 2010 [1], while Asia Pacific's B2B EC is forecasted to grow rapidly at a Compound Annual Growth Rate (CAGR) of fifty-nine percent [3]. Specifically in Australia, EC is estimated to be worth $\$ 11.3$ billion dollars annually [4].

\subsection{Research Problem}

According to the report of the Information Economy [36], Australia is well positioned to benefit from the emerging information economy. On a number of metrics, Australia is among the leading nations in terms of measures of Internet infrastructure, penetration and activity. In fact, Australia is ranked the top second country in Asia Pacific region by EC infrastructure [15]. However, in comparison with other countries and larger Australian businesses, small- and medium-sized enterprises (SMEs), have been relatively slow in adopting EC [36],[46]. Definition of Smalland Medium-sized Enterprises (SMEs) in Australia is any business employing less than 20 people; and 20 or more but less than 200 people for medium business. For further definitions of SMEs, please refer to http://www.sbdc.gov.au. Even if SMEs were able to overcome the barriers of initial adoption, they still face challenges when trying to implement the new system into their business. Most SMEs perceive the challenge of integrating EC into their business operations as risky, complex, time-consuming, and an expensive initiative [36]. Yet it should be noted that if EC implementations are successful, the potential benefits to small businesses can include increased sales, improved profitability, increased productivity, reduced costs associated with inventories, procurement and distribution, improved quality of service, and secured competitive positions (see [14], [20], and [48]).

The need to adopt EC for survival in the international marketplace, especially due to physical and economic distance faced by Australian SMEs is imperative. An awareness of the critical success factors of EC implementation also becomes essential for SMEs to appropriately address the relevant issues and move forward, since failed implementation may have severe repercussions on small businesses with their limited resources. Despite the salience of these issues, there is little empirical research that examines the success of EC deployment after the technology has been implemented. In addition to that, there is little of the prior Information Systems (IS) and Information Technology (IT) literature, and none from EC literature, that has investigated the relative importance of the identified factors of extent of deployment. Without knowing the relative importance of these factors, SMEs may be expending their limited resources and energy on less important factors which have limited contribution to EC implementation success. Hence, the principal contribution of the current report can be asserted to be its provision of a model for EC adoption that takes into account the relative importance of various factors that encourage or inhibit the extent to which it is deployed. It may also provide a theoretical tangent that authors and facilitators of future research may wish to follow.

\subsection{Scope of Study}

In this study, the term Electronic Commerce (EC) principally includes, but is not limited to, Internet-based EC. The scope of EC applications is limited to the utilisation of the Internet as the technological infrastructure to communicate, distribute and conduct information exchange and transactions with business partners. The overwhelming growth rate of the Internet since the commercialization in the mid 1990s makes it the most utilised Wide Area Network platform even for business-to-business communications, and makes the further substitution of previous platforms highly likely throughout the next decade. It is estimated that 53 percent of EC capabilities will be based on business-to-business relationship, and the Forrester Research predicted that B2B EC was to hit US\$12.2 billion in 2006 worldwide [16]. It is now universally recognised that B2B EC possesses the largest potential in the EC segment [19], which is supported by a growing trend of companies incorporating one or more of its business initiatives in e-procurement, CRM, online sales and supply chain management. This study is purposely focused on organisations that use business-to-business EC to carry out transactions and interactions that affect existing business relationships or preexisting contractual relations between trading partners.

\subsection{Research Objectives}

In response to the current issues faced by SMEs, an awareness of the critical success factors of EC implementation would provide these organisations with the required knowledge to appropriately address the relevant concerns and move forward in the area of EC. Using the Extent of Deployment as the indicator of implementation success, the study aims to address the following research questions:

1. What factors influence of the extent of EC deployment for SMEs?

2. To what degree do these individual factors influence the success of EC implementation? 


\section{Theoretical Background}

It should be noted that this study has been informed by a substantial variety of previous research on adoption, implementation, and innovation diffusion theories applied to technology in general: Information Systems (IS), Information Technology (IT), Electronic Data Interchange (EDI), Inter-Organisational System (IOS), and Management of Information Systems (MIS). Clearly, EC is not identical with any of them. It necessarily involves IT which it shares with IS and MIS, and at more sophisticated levels is likely to enable EDI. It is also undeniably 'Interorganisational'. It may therefore be argued that any factor that has been shown to influence the adoption and implementation of technology or application in general is worthy of consideration as a potential explanatory variable with respect to EC. To ensure thoroughness, wherever previous research or reasoning suggested a relationship between a factor and one of the variables, its possible influence on the focal variables will also be hypothesised. Innovation diffusion theories have been particularly useful for understanding the facilitators and inhibitors of EC, which can be asserted to be a sub-type of innovation. After a critical analysis of existing models, their influencing factors, stages, and process, the theoretical framework is extended to incorporate important organisational and contextual aspects of adoption and implementation in the development of a research model.

\subsection{Electronic Commerce Adoption and Implementation}

As defined in Roger's diffusion theory [45], adoption is a decision to define the full use of an innovation as the best course of action, and implementation is taking the necessary steps to facilitate and execute that innovation into business practice or process. For several reasons, there is rarely any clear separation between adoption and implementation in EC. In other words, EC is not "one simple or single innovation" that a firm either does or does not adopt, but should be considered as consisting of a number of combinations of innovations of varying complexity and sophistication on a continuum requiring lesser to greater levels of commitment. While conceptually distinct, there is no temporal dividing line between all the dependent variables in this study for they merge into one another (i.e. State of Adoption, Extent of Deployment, Level of Usage, and Overall Satisfaction). Rather, their hierarchy is logical in that each is a necessary condition for the next: whilst one feature is becoming more utilised, another is being explored and a third is being considered or enabled. Thus, in any firm EC is never "adopted" or "not adopted", but always in one of a large number of possible 'states of adoption'. The following section focuses on discussing the significance of Extent of Deployment as a measure of implementation success. The other three dependent variables are beyond the scope of this paper.

\subsection{Extent of Deployment}

Whilst most IS adoption studies are inwardly oriented (due to the internal deployment of systems architectures or software within a specific firm), the current study utilises Extent of Deployment as an externally-oriented measure. Hence, the definition of Extent of Deployment can be designated as the degree to which a firm is successful in linking with external partners and converting its transaction documents into electronic form. The construct borrows three concepts and definitions from diffusion and integration studies by Massetti and Zmud [31]. A weighted index was developed to measure Extent of Deployment by multiplying all the three components of deployment (or the 'extent of integration' or 'diffusion' as defined by previous studies - see [31], [42], [43]). Although it is an adaptation of concepts from previous research, the current report has tailored these for an EC context. Thus, the variable Extent of Deployment combines the notions of volume, diversity, and breadth. As for the aspect of depth, this is captured in the other dependent variable not covered in this paper - the Level of Usage.

1. Volume - the proportion of business that the firm derives from Internet-based EC is defined as the "Percent of Business Conducted Online" in this study.

2. Diversity - the variety of documents exchanged via Internet-based EC with their external partners. It is defined as "Application Diversity" in this study.

3. Breadth - the extent to which a firm has developed EC connections with its trading partners. It is defined as "Number of Linkages" in this study.

Unlike traditional information systems, EC is an Interorganisational System (IOS), and therefore requires the organisation to expand its external electronic links to gain economies of scale and be cost effective. Previous studies have demonstrated that there is a need for "inter-exploitation" between partners through expansion of IOS in order to sustain strategic advantage [2]. Firms could utilise the electronic links to a greater extent by including more transactions or documents. Such an expansion of electronic exchange would enable firms to experience the full benefits of EC and an improvement in organisational effectiveness in the long run 


\section{Research Model}

In this study, it is proposed that several factors influence different levels of EC adoption for the organisation. To assist in the selection of the most significant variables for EC adoption and implementation, a number of possible relevant factors have been identified and grouped into broad categories of internal and external environmental factors. The principal reason for separating internal from external influences is to distinguish between organisationderived factors and other motivations that may arise from the overall business environment (or outside the organisation). Figure 1 presents the research model in which the relationship between the influencing factors and the Extent of Deployment was examined.

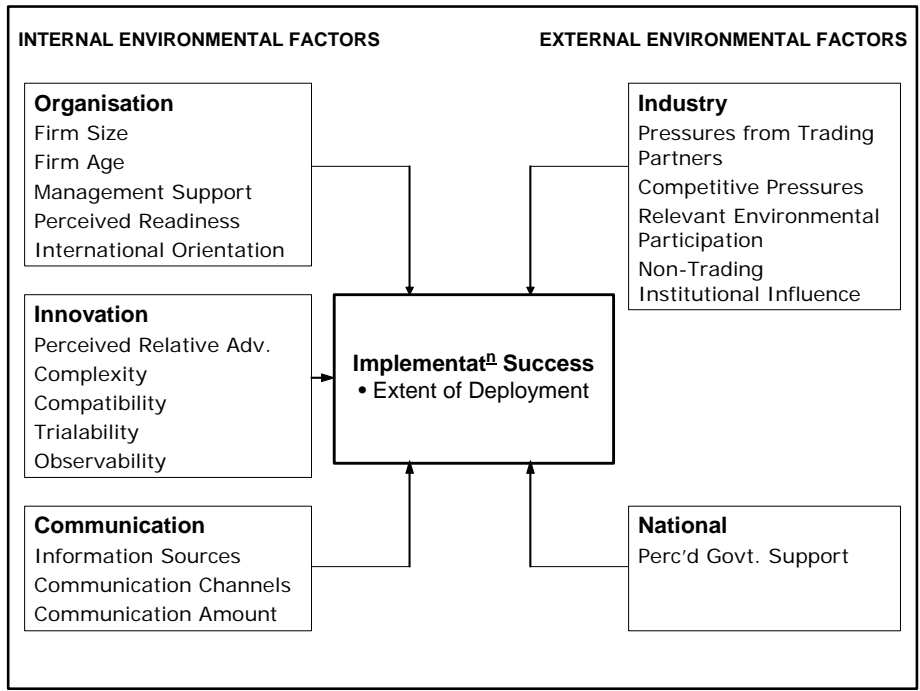

Figure 1: Conceptual Model of Factors that Influence the Extent of Deployment of EC

\subsection{Influencing Factors of EC Adoption and Implementation}

\section{Internal Environmental Factors}

Despite the advantages of EC, SMEs around the world are not adopting it as rapidly as originally anticipated [14], [21], [32], and [52]. Several organisational factors that inhibit IT and EC adoption were identified after conducting preliminary interviews and an extensive literature search. Among these were the cost of technology, a lack of managerial and technological skills, a lack of system integration and a lack of financial resources [8],[23],[32],[37],[48]. These inhibitors are expected to play a major role in the context of small organisations, where resources and the level of computer sophistication are limited [14],[21],[30],[48],[53], thus firm size and perceived readiness are included in the category of internal environmental factors. Another recurrent observation is that EC adoption seems to be more of a management issue than a technical one [7]. Many researchers have found that if there is a lack of support amongst top executives, technology cannot be successfully adopted [6], [20], [30], and [40]. It is therefore reasonable to assume that management support is a critical factor to the successful adoption of EC. Previous scholars also anticipated that the age of the firm could either foster or impede technology adoption in terms of resistance to change, a track record of successfully overcoming hurdles, and experience in adopting prior technological advances [18]. The international orientation of the company is also examined in this study, as previous research within the area of Internet adoption demonstrates that firms that are operating in the international markets are more likely to conduct EC through portals than those that do not have foreign collaborations (see [12],[29],[52]).

Several factors that influence the adoption of innovation are deduced since EC is treated as the innovative business practice in this study. Of most commonly investigated characteristics that promote the adoption of innovation, the best known may be those developed by Rogers [45]. These innovation factors have also been the key feature of several other IT adoption studies [23],[28],[34],[51], and EC studies [28],[30],[32],[52]. In this study, they are adapted for the current report as follows: perceived relative advantage (i.e. the perceived EC benefits and impact relative to its existing practice or system), compatibility (how well EC fits in both technical and organisational processes), trialability (the degree to which EC can be pilot tested or experimented without high start-up costs), complexity (ease of use or the ease with which EC can be learned) and observability (the extent to which EC advantages or gains are visible to firms).

According to the findings of preliminary interviews and an extensive literature search, there is a lack of reliable sources of information that SMEs can exploit in order to gain knowledge of EC. This may serve to hinder the smooth adoption of EC in many cases. Moreover, following the work of Rogers [45], other scholars argue that the adoption of 
a new technology is influenced by communication channel types (mass media vs. interpersonal channels), information source (external source vs. internal source) and communication amount [3], [37]. Hence communication factors were added to the EC adoption model.

\section{External Environmental Factors}

SMEs are usually characterised by a high level of environmental uncertainty that includes fluctuations in interest rates, reliability of supply, and competition. Related to this factor, the use of IT and EC is often imposed on SMEs by major customers or suppliers. Such pressure from trading partners plays a critical role in encouraging small firms to adopt IT and EC, as evidenced in previous studies [12], [21], [23], [32], [52], and [53]. In addition, the competitive pressure that firms face within the industry also has an influence on the company's decision to adopt IT or EC [10], [20], [21], [23], [32], [52], and [53]. As more competitors adopt EC, small firms are more inclined to follow suit in order to maintain their own competitive positions. Even though it should also be noted that the influence of non-trading institutions such as industry associations, government, financial institutions, the media and universities may not be as strong as that of the entities the firm trades with, they may still influence the adoption of EC to a certain extent. Thus, the aforementioned justifications lead to the inclusion of trading partner's pressure, competitive pressure and non-trading institutional influence under the category of industry factors. Relevant environmental participation is also an important factor for any firm that is trying to employ new technology or systems to their fullest potential. Without the wide acceptance of applications or systems, current or potential customers may resist the adoption of EC because of the lack of infrastructure, suitable platform, or compatible technological standards [30], [32], [52]. It should be noted that although relevant environmental participation recognizes the existence of a possible critical mass, it is not synonymous with that term. While the concept of critical mass may be appropriate to studying the movement of a single innovation through a large social system, its usefulness when applied to innovations that lie on a continuum (such as EC in SMEs) is limited.

Finally, the national factor is included in the adoption model in order to provide a macro country-level view of EC, its adoption behaviour and the business environment. This study demonstrates that in addition to the private sector, the governmental sector can also act as a crucial catalyst in stimulating a successful adoption experience for the SMEs (see [20], [52]). Previous studies have illustrated that governmental support in funding infrastructure projects, adoption schemes and initiatives have provided direct and indirect stimulation to the supply of information which - as a consequence - produces faster technology diffusion. Governmental subsidy and supports have been demonstrated to have a positive impact on the uptake of IT use and innovative business practice by organisations, especially SMEs [39], [52]. Institutional regulations that promote electronic interactions and transactions may also encourage EC or future IT adoption in small businesses [27], [44]. In this study, we examine the influence of governmental support and its propensity to shape the push for EC in SMEs.

\section{Research Methodology}

At the time of the study, an exploratory approach was taken to consider a comprehensive scope of factors that may influence the implementation success of EC. Thus, a cross sectional approach was undertaken and a framework was enacted to measure firms' responses with respect to the implementation of EC. The desired result in testing the model is the identification of factors associated with the Extent of Deployment.

\subsection{Data Collection}

The study was conducted in Australia in three phases: a preliminary investigation, pilot study and questionnaire survey. Preliminary interviews with five Australian SMEs alongside with extensive literature review were conducted to provide direction as to what implementation factors are imperative to SMEs; all of which contributed to the design of the proposed research model. A survey instrument with questions and multiple-item scales was developed and pilottested to capture the information reflecting the perceptions and practice of those adopting EC. In order to focus on SMEs, assistance was sought from governmental and research institutions in Australia to develop a database of such companies and contact details of target respondents. The best available sampling frame in Australia appeared to consist of a combination of database from the Small Business Directory in Western Australia (Department of Commerce and Trade) and Small Business Unit (SBU) of Curtin University of Technology. A systematic random sampling method was conducted and a total of 485 records were derived from a database of 3232 companies.

As the survey was intended to apply to a wide geographical area, the chosen method of delivery was a combination of email, web and mail survey. A cover letter stating the objective of the study and the web address of the online version of the survey was included. The questionnaires were personally addressed to the director or owner of the firms. In order to improve response rate, reminders were sent out to target respondents two weeks after the commencement of first and second-wave of mail-outs. A total of 115 usable responses were collected, amounting to an acceptable rate of 23.7 percent of responses.

To arrive at an estimate of total non-response error, a comparison of the data obtained from the two mailing rounds was conducted. The basic assumption behind this approach is that subjects that respond only after further prompting were potential non-respondents. Analyses from the first round of respondents are compared with results from later 
rounds and no statistically significant difference is found between the two groups. Thus, it is reasonable to assume that non-response error is not present and that the remaining non-respondents exhibit similar characteristics to the respondents. As such, it is safe to make the assumption that the data obtained from the respondents was representative of the sample and that, as a consequence, any findings derived from this data were generalisable to the sample frame in its entirety.

\begin{tabular}{|c|c|c|c|}
\hline \multicolumn{4}{|c|}{ DEPENDENT VARIABLES } \\
\hline Variables & Indicators & Measurement & Adopted /Adapted Sources \\
\hline \multicolumn{4}{|c|}{ Implementation Success } \\
\hline Extent of Deployment & $\begin{array}{l}\text { Combination of application diversity, } \\
\text { number of linkages, \& proportion of } \\
\text { business conducted online }\end{array}$ & Ratio Scale & [31] \\
\hline \multicolumn{4}{|c|}{ INDEPENDENT VARIABLES } \\
\hline Variables & Indicators & Measurement & Adopted /Adapted Sources \\
\hline \multicolumn{4}{|c|}{ Organisational Factors } \\
\hline Management Support & $\begin{array}{l}\text { Composite of perceived mgmt support } \\
\text { items }\end{array}$ & Likert Scale & [23] \\
\hline Perceived Readiness & Overall perceived preparedness & Likert Scale & [23] \\
\hline Firm Size & Number of full-time equivalent employees & Ordinal Scale & {$[11],[17]$} \\
\hline Firm Age & $\begin{array}{l}\text { Number of years the firm has been } \\
\text { established }\end{array}$ & Ordinal Scale & Researcher Defined \\
\hline $\begin{array}{l}\text { International } \\
\text { Orientation }\end{array}$ & $\begin{array}{l}\text { Proportion of turnover derived from } \\
\text { international trade }\end{array}$ & Ratio Scale & [29] \\
\hline \multicolumn{4}{|c|}{ Innovation Factors } \\
\hline $\begin{array}{ll}\text { Perceived } & \text { Relative } \\
\text { Advantage } & \end{array}$ & $\begin{array}{l}\text { Composite of perceived relative advantage } \\
\text { items }\end{array}$ & Likert Scale & [45],[47] \\
\hline Compatibility & Composite of perceived compatibility items & Likert Scale & {$[45],[47]$} \\
\hline Complexity & Composite of perceived complexity items & Likert Scale & {$[45],[47]$} \\
\hline Trialability & Composite of perceived trialability items & Likert Scale & {$[45],[47]$} \\
\hline Observability & Composite of perceived observability items & Likert Scale & {$[45],[47]$} \\
\hline \multicolumn{4}{|c|}{ Communication Factors } \\
\hline Information Sources & $\begin{array}{l}\text { Variety of material \& organisation sources } \\
\text { that firms used to attain information about } \\
\text { EC }\end{array}$ & Ratio Scale & Researcher Defined \\
\hline $\begin{array}{l}\text { Communication } \\
\text { Channels }\end{array}$ & $\begin{array}{l}\text { Variety of channels firms used to delivery } \\
\text { information about EC }\end{array}$ & Ratio Scale & Researcher Defined \\
\hline $\begin{array}{l}\text { Communication } \\
\text { Amount }\end{array}$ & $\begin{array}{l}\text { Frequency of communication between the } \\
\text { firm \& its trading partners }\end{array}$ & Ordinal Scale & {$[3],[33]$} \\
\hline \multicolumn{4}{|c|}{ Industry Factors } \\
\hline Customer Pressure & $\begin{array}{l}\text { Level of perceived pressure exerted from } \\
\text { customers to adopt EC }\end{array}$ & Likert Scale & [23],[41] \\
\hline Supplier Pressure & $\begin{array}{l}\text { Level of perceived pressure exerted from } \\
\text { suppliers to adopt EC }\end{array}$ & Likert Scale & [23],[41] \\
\hline Competitive Pressure & $\begin{array}{l}\text { Perceived competitor influence on the } \\
\text { adoption of EC }\end{array}$ & Likert Scale & [23],[41] \\
\hline $\begin{array}{l}\text { Relevant } \\
\text { Environmental } \\
\text { Participation }\end{array}$ & $\begin{array}{l}\text { Composite of participation of specified } \\
\text { related organisations in the business } \\
\text { environment which the firm operates in }\end{array}$ & Ordinal Scale & Researcher Defined \\
\hline $\begin{array}{l}\text { Non-Trading } \\
\text { Institutional Influence }\end{array}$ & $\begin{array}{l}\text { Composite of perceived influence of } \\
\text { specified non-trading institutions }\end{array}$ & Ordinal Scale & Researcher Defined \\
\hline \multicolumn{4}{|c|}{ National Factors } \\
\hline $\begin{array}{l}\text { Level } \\
\text { Governmental } \\
\text { Support }\end{array}$ & $\begin{array}{l}\text { Perceived level of support provided by the } \\
\text { government to adopt EC }\end{array}$ & Likert Scale & Researcher Defined \\
\hline
\end{tabular}

Table 1: Original Construct Measurement 


\subsection{Instrument Development}

The questionnaire used in this study was design to measure variables in the theoretical model illustrated previously. Some of the indicators were developed by the researcher, while some were adopted or modified from previous scholars. In some cases in which a previous measure is adequate, sources and proper credit were cited. In other cases, new indicators were added and compared with the previous measures to help improve the explanatory power of the research model. Slight modifications of the wordings were made to reflect the business-to-business EC nature of the study and any further changes to the instrument were retested and then included in the final survey.

Table 1 represents a comprehensive list of the variables used in the current study. These variables are presented with the corresponding indicators, the types of scales used, and an indication of whether they were researcherdefined, adopted, or adapted from other sources. Researcher-defined variables are developed according to [35] suggestions for constructing new measure.

In the current report, all variables were measured as attitudinal perception items on five-point Likert scales (e.g. 1 to $5=$ very unimportant to very important; strongly agree to strongly disagree). The research instrument was based on many multiple-item scales, as incorporating several items results in a more realistic and comprehensive indicator [35]. To ensure the validity of the dependent measure, this study also incorporates a single rating scale so as to provide a comparison of results.

\section{Dependent Variable: Extent of Deployment}

It was stated in the previous section that Extent of Deployment measures the degree to which the firm is successful in linking with external partners and converting its transaction documents into electronic form. Thus, Extent of Deployment is measured by multiplying all the three components of deployment - volume, diversity and breadth of EC application as implemented within the business practice.

Owing to the exploratory nature of the research at the time the current study was conducted, the relationships that emerged as significant at the 10 percent level may or may not eventually prove to be valid in a more intensively formed undertakings. However, they were deemed to be worthy of serious consideration in this report as a basis for further exploration. In addition, due to the sample size limitation of this study, a rigid imposition of the traditional 5 percent level of significance level $(p<0.05)$ entailed an unwarranted risk of rejecting possible valid relationships (i.e. type II error). According to Hair, Anderson, Tatham and Black [22], the recommended minimum ratio of cases to variables in regression is five to one. In this study, this criterion has also been met.

\subsection{Reliability and Validity Testings}

As recommended by [38], the reliability and validity of the measures for this study were tested to ascertain the suitability and rigour of the study instrument. The Cronbach's coefficient [9] alpha has been used in the present research to examine the internal consistency of the scales relating to all the independent variables of this study. The principles recommended by [35] were followed to ensure the reliability of the current study:

1. Clarity of most constructs were carefully examined. Most of which have already been established in previous literature.

2. Pre-tests and pilot studies were used.

3. The most precise level of measurement was used in each question within the constraints of meaningful discernibility of values. A 5-point scale is used in the questionnaire.

4. Multiple indicators were used where any possibility of ambiguity existed on the part of the respondents.

A test of internal consistency amongst each set of items representing the Internal and External Environmental Factors was conducted. These tests reveal that the Innovation Factors - Perceived Relative Advantage (0.73), Compatibility (0.77) and Complexity (0.72) and Observability (0.79), all had Cronbach Alpha values greater than the 0.7 benchmark suggested by [38]. The value for Trialability (0.56) was marginally below the cut off value of 0.6 , acceptable in the early stages of research [50]. The reliability coefficient for the new variables, Management Support (0.94), Non-Trading Institutional Influence (0.98), and Level of Usage (0.74) all exceeded 0.7. Thus, overall the results appeared robust enough to carry out further analysis. The issue of face validity in the case of previously recognized concepts is taken as established. The researcher-defined concepts naturally awaits general acceptance. Content validity is achieved during the planning and construction stages of the scale and not when the scale is completed, hence procedures that are used to develop the instrument are the key to content validity. Various indexes such as the Management Support, Organisational Readiness, Innovation Factors and the Communication Factors have already been tested, as many of these measures contain items or components that have been borrowed or adopted from previous studies. As dependent variable like the Extent of Deployment have not previously been used in studies of this kind, it was appropriate that its content validity be given some consideration. Guided by the procedures suggested by Davis [13], the following steps were taken to address the issue for the variables mentioned above:

1. A literature search to examine all possible items to be included.

2. The utilisation of multiple judges to assess the appropriateness of the items included. 
3. Pre-testing the scale on a small sample of target respondents so as to identify potential flaws with the contents and /or wording.

4. Any potentially questionable item was discussed with a range of experts and practitioner in the area of EC for clarification.

5. The modification of the scales based on suggestions developed from steps (2) and (3).

\subsection{Assumption Testing and Multicollinearity}

As noted in the Table 2 below, this study exceeds the standards of regression by scoring less than 10 for its Variance Inflation Factor (VIF), which is a minimum of Tolerance value of 1.0. In addition, the Durbin Watson statistics fell within the range of 1.5 to 2.5 .

\begin{tabular}{lcc}
\hline \multirow{2}{*}{ Model } & \multicolumn{2}{c}{ Collinearity Statistics } \\
\cline { 2 - 3 } (Constant) & Tolerance & VIF \\
MGMT.SUPP & 0.933 & \\
INTL.ORIENT & 0.876 & 1.072 \\
PCD.REL.ADV & 0.857 & 1.142 \\
TRIALAB & 0.876 & 1.167 \\
INFO.SRC & 0.867 & 1.142 \\
COMM.AMT & 0.895 & 1.153 \\
COMP.PRES & 0.716 & 1.117 \\
NON.TRD.INFL & 0.719 & 1.396 \\
\hline
\end{tabular}

Durbin Watson Statistics $=2.046$

Table 2: Assumption Testing - Coefficient of Extent of Deployment

The existence of outliers was queried and none were found. All assumptions were satisfied, suggesting no serious deviations from normality and no serial correlation of errors in this study.

\section{Results}

\subsection{Sample Profile}

Of the 485 survey questionnaires distributed to target respondents within Australia, a total of 115 usable responses were collected. More than 50 percent of the responding firms employ less than 50 workers. The distribution of respondents was consistent with the overall community distribution - 41 percent of respondents came from manufacturing industry, 20 percent from import and export business, 18 percent from retail, 11 percent from wholesaling sector, and the remainder from other sectors. The information collected indicates that the respondents are not only distributed across industry sectors but also various business types and turnover levels. These data were compared with the Australian Bureau Statistics to gauge the representation of the sample. The comparison showed that no groups or category were seriously under or over represented. Other sample profile such as the title of respondent, serves as an indicator of the credibility of information provided by the key informant. The majority of those who responded in this study held Managing Director positions in their respective companies and three quarters of them had tertiary education or above. This suggests that the level of language used in the survey is unlikely to have been any hindrance to its proper interpretation by the respondents. 


\subsection{Empirical Testing of the Research Model}

Multiple linear regression was used to generate the results illustrated in Table 3. It represents the results of the stepwise-backward elimination, whereby those factors that are statistically significant in the model for the Extent of Deployment, are retained.

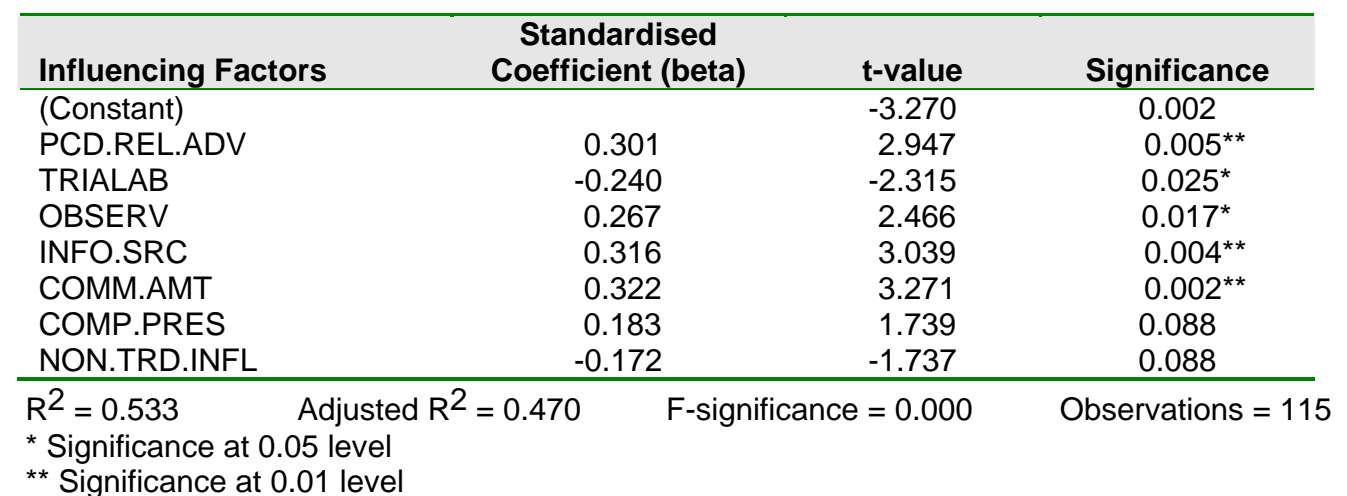

Table 3: Final Model Estimation (Stepwise-backward Method) for the Extent of Deployment

An adjusted R-squared value of 47 percent of the variation in Extent of Deployment by Australian SMEs is explained by the variation of Communication Amount, Variety of Information Sources, Perceived Relative Advantage, Observability, Trialability, Competitive Pressure, and Non-Trading Institutional Influences (F-significance < 0.000 ). All variables are significant at the 0.10 level or better. The figure below shows factors that are supported by significant evidence.

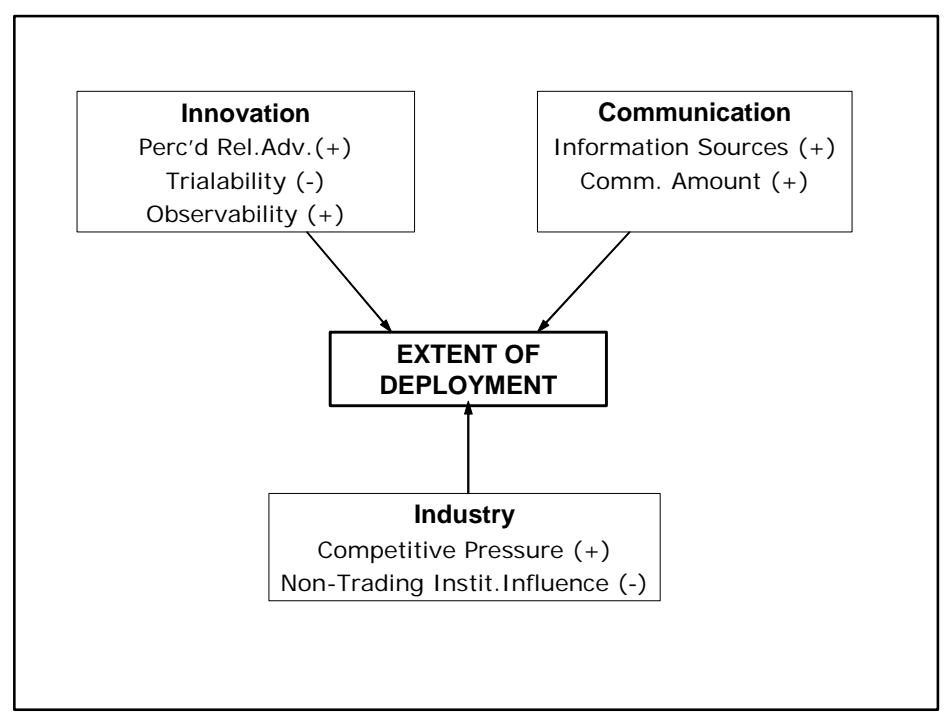

Figure 2: Factors related to the Extent of Deployment among Australian SMEs

\section{Discussion}

\section{Communication Amount}

Communication Amount is the most significant factor related to the Extent of Deployment thus suggesting that the more a firm increases its intensity of communication with other organisations, the higher its extent of deployment is likely to be. It can also be rationalised that the greater the amount of information a small firm shares with its trading partners, the greater the diversity and depth of integration of EC will be between firms. Since EC can be regarded as another interorganisational system, more frequent communication between trading partners will help them coordinate policies, provide technical information, and answer questions. Such collaborative approaches may assist, in a fairly unobtrusive manner, in bringing the trading partners "on-board" to the EC network. This would in turn help them in the uptake of new systems, which would eventually motivate the adopting firms to improve the extent of their EC deployment. 


\section{Variety of Information Sources}

The Variety of Information Sources used to attain information pertaining to EC, is found to be positively related to the Extent of Deployment. This suggests that the larger the variety of sources a firm used in acquiring information about EC, the higher the Extent of Deployment. This can be explained in the following way: as firms are getting ready to implement EC, they are likely to seek advice and information from a large variety of sources in order to familiarize themselves with the different functions, applications, or benefits of EC. The larger the variety of the sources the firm consults, the higher possibility will be that the firm would seek diversification of applications and external participants for higher levels of deployment. It may also be suggested that the diligence on the part of the firm that seeks information from a greater variety of sources will result in them being better informed than those relying on a smaller sample of sources. Since those companies that have consulted widely are likely to have more knowledge in the requisite areas of EC, they are more likely to apply their knowledge to practical functions and applications- This would conceivably lead to a higher ability to trade with a variety of participants in the market, thus encouraging them to attain a higher proportion of business online.

\section{Perceived Relative Advantage}

Perceived Relative Advantage appears to be significantly related to the Extent of Deployment. This contradicts the results of a study by Premkumar, Ramamurthy and Nilkantan [42] in which they found that perceived relative advantage only influences the adoption decision and not the implementation success of EDI. The high relative importance of this variable indicates that the benefits of EC perceived by SMEs have led to a high extent of deployment. This can be logically explained in so far as it is akin to assessing the benefits and costs of adopting any type of innovation. In this case it can be seen that SMEs are most motivated by the prospects of gaining a relative advantage over competitors, or by the likelihood that EC can put them ahead of the "status quo" or existing business practice in as much as it might open up new markets for them or lower their business costs. On the other hand, it could be suggested that if companies do not believe that EC can provide them with relative advantage after they have already adopted it, it is likely that the implementation would be discontinued.

Although one cannot forcibly increase ones' perception of relative advantage where it does not genuinely exist it is nevertheless possible to be more proactive in investigating and exploring possible advantages that could lead to increased success [5]. SMEs should evaluate their implementation of EC on a regular basis in order to integrate and expand its application to other business functions effectively. After making the decision to adopt EC, it also needs to be perceived by SMEs as a better alternative to existing practices in the business. However, very often the lack of knowledge of the advantages that EC offers can cause impatient firms to give up and discontinue the adoption and implementation. Therefore, the use of promotional efforts and non-coercive influence tactics is suggested for increasing the levels of awareness for EC benefits. Perhaps both government and industry associations can also play a more active role raising participation, pointing SMEs to the opportunities and benefits of EC, providing them with support, and working with them to overcome their doubts regarding the implementation of EC.

\section{Observability}

For Australian SMEs, Observability appears to be significantly related to the Extent of EC Deployment. A two-way causation is likely to be operating in this instance. Firstly, there is a logical relationship between confidence and Extent of Deployment. When a firm can observe the benefits that EC has brought to the business, it is very likely that the firm will increase the depth and breadth of EC implementation. In the case of doing business online, effects such as quicker access to and dissemination of information and savings in costs (e.g. printing, advertising, communication and overheads) are more immediate and easier to acknowledge. The implication for SMEs is therefore to highlight the easily and quickly demonstrable benefits and usage in the first instance, such that the short term visible effects of EC can help promote its continued adoption and hence facilitate the long-term goals of the initiative. It is sometimes not enough to assume that people will automatically realise the impact of an innovation. Indeed, it may be necessary to insist that firms reflect on their EC implementation in order to increase their awareness and observation of the regimen's impact. This could include the requirement of a formal review procedure involving both owner/managers and employees of a given company, in order to elicit the end user observations of how well the application of the EC systems is progressing. During the course of implementing EC a degree of pessimism may be exhibited amongst key personnel, and this may be a justifiable reaction to a certain extent. Nonetheless, every effort must be made to counter unjustified and groundless pessimism because this could serve as a needless inhibitor in the deployment of EC. This may well require a more proactive approach in which SMEs will need to be courageous enough to implement an EC system, even if its tangible benefits are not readily observable from the outset.

Another possible explanation for the significant relationship between observability and extent of deployment could lie in reversing the chain of causality as follows: the higher the extent of EC deployment, the greater the likelihood that the regimen's advantages will be observable. It is logical to expect that the more extensive the deployment of EC is in terms of its application to a given firm's business practices, the more benefits the firm is going to reap. These benefits will in turn become more observable to the adopting firms and confidence in EC will thus be selfperpetuating. To improve the extent of EC deployment, firms should not only increase the variety of documents exchanged via the Internet, but also seek to increase external links with trading partners. This can be done by 
providing incentives and assistance to encourage these partners to get involved in the electronic network. Such incentives may include, for instance, bulk discounts or special rates for trading online.

\section{Trialability}

It was interesting to note that Trialability appears to be inversely related the Extent of Deployment. It is possible to suggest that when adopting firms perceived EC to be less trialable, they are more likely to push for higher levels of commitment. Such firms would thus apply more urgency to learning and experimenting with the new system, which normally leads to greater preparedness as most companies want to ensure that their investment will not be wasted. This also indicates that such firms would have a higher ability to deploy extensively. Another possible explanation, however, is that the perception of trialability may be a sign of lack of commitment. Because deployment requires some degree of commitment, it can only truly begin when the trialing mentality stops. This serves as a reminder to would-be or hesitant adopters that even though preparation and keen attitude in experimenting may be essential, SMEs should not take too long to deploy EC. For a start, rather than purchasing more expensive, custom-developed EC software or applications, well-tested dedicated packages may well suit the needs of the company.

\section{Competitive Pressure}

Competitive Pressure was positively related to the Extent of Deployment, suggesting that the higher the level of pressure experienced to the firm from its competitors, the greater the extent of its EC deployment is likely to be. This means that the competitiveness of the environment has been found to provide the "push" for SMEs to deploy their existing capabilities. Firms that fear losing customers or market share may expedite their learning process or expand the use of new systems in order to keep up with what their competitors are doing. The emergence of competitive pressure as a key variable also underscores the need to electronically integrate business operations both internally and externally with trading partners. Formalisation of these functions and trading processes is essentially a matter of deployment. SMEs are advised that early formalisation of a system between the firm and its trading partners may decrease the likelihood of the trading partners finding a competitive relationship more attractive. By being more efficient in business transactions with their partners through faster and more accurate processing, the competitiveness of a given firm would naturally be strengthened, and better links with its customers would be formed.

\section{Non-Trading Institutional Influence}

Non-Trading Institutional Influence was found to have an inverse relationship with the Extent of Deployment. This suggests that those autonomous early adopters that are less likely to be influenced by the publicity and persuasion of certain institutions (such as governments, banks, telecommunication corporations, media, consulting firms or universities), may tend to explore the possibilities more widely and with greater initiative. Alternatively, those that tend to follow what others prescribe (e.g. laggards or non-initiators) tend to lack the characteristics or incentives to explore, take risks, adapt to new change, and to venture into different avenues for maximising the potential of new business practices (in this case, adopting EC). It may also be true that when firms react to pressure from the external environment, it is more likely that they are limiting their deployment in the direction from which the pressure is arising instead of exploring the fuller extent of possibilities that the innovation (EC) offers. This can impede wider deployment as some firms may see it as a chore to keep following others, while some may be discouraged to further the adoption due to unreadiness or unclear objectives. Thus, SMEs are strongly encouraged not to restrict their exploration of possibilities as a result of the dominance of narrow influencing sources. Nonetheless, it should be noted that despite the relationship between Non-Trading Institutional Influence and Extent of Deployment being statistically significant, it is a comparatively weak relationship.

\section{Conclusion}

It is clear that in the implementation of EC, most SMEs in Australia face a range of challenges including a lack of perceived relative advantage over current systems, lack of visible improvement or benefits, competitive pressure, and insufficient sources of information for further deployment. This study offers a comprehensive framework and knowledge of the relative importance of factors that influence EC deployment which would assist SMEs to better plan their continuous IT and resource investments. To achieve a greater extent of EC deployment, it is imperative for SMEs to possess an enduring perception of EC as being advantageous over preceding legacy systems and that its implementation can give them an advantage over their competitors. In fact, Grandon and Pearson [20] even asserted that late adopters may not gain competitive advantage as much as they may gain competitive parity because most of the surplus value of EC implementation would be ceded to the earlier adopters. Thus, apart from encouraging hesitant firms to stop procrastinating and begin making a commitment, it is also essential for SMEs to possess a sufficient degree of optimism and confidence such that a habit of continued deployment becomes the norm for future adoptions of innovation. When obtaining information about EC, SMEs should consult more than one source of information to better its knowledge about its applications and benefits, as well as its potential pitfalls. However, whilst external information sources are valuable, a thorough assessment of a firm's own business needs may still be required to prevent the type of unfounded influence which commonly leads to limited deployment or discontinuity of implementation. It was also found to be beneficial for SMEs to increase the frequency of communication with their trading partners. This often enhances collaboration between the firms, establishes trust, and integrates future online business more extensively. The current study also suggests that SMEs should take more initiative in their 
deployment strategies, as an impulsive reaction to pressures coming directly from competitors and non-trading institutions tend to limit the fuller potential of what EC has to offer.

Apart from conceptualising the theoretical framework of EC implementation success for SMEs, the current study has also helped to develop the definition of the concept and the measurement of Extent of Deployment. Moreover, it encapsulates a multi-dimensional measure of implementation success combining the notions of volume, diversity, and breadth, whilst encompassing both an external and internal orientation.

The exploratory nature of the current report has helped in identifying associations between variables from which more confirmatory or causally directional hypotheses can be generated in the future. Here the technique of Structural Equation Modelling may be usefully applied. It would also be insightful to conduct longitudinal studies to help clarify the direction of causality and to test for feedback effects in adoption and implementation. In this particular study, no attempt was made to control for industry type. The models may be tested more intensively in a chosen or specific industry. In making generalisations from the research sample, one has to take into consideration the context of Australia. The findings may not be universally true, but they are likely to be applicable in similar cultural contexts. Comparisons of the research model can be conducted over several countries, particularly from different geographical regions. The contrasting contexts may provide some interesting results. Lastly and most importantly, having established the soundness of the theoretical framework of extent of deployment for SMEs, other researchers may investigate its applicability to a wider range of business communication technologies and further innovations in the future.

\section{References}

[1] Australian Government Information Management Office. E-Government: Australia's Approach, Keynote Address Special Minister of State Senator The Hon Eric Abetz, Commonwealth of Australia, In Proceedings, Nikkei $5^{\text {th }}$ Strategic Conference on e-Government, Tokyo, Japan, 2005.

[2] J. Y. Bakos, Information Links and Electronic Marketplaces: The Role of Interorganizational Information Systems in Vertical Markets, Journal of Management Information Systems, vol. 8, no. 2, pp. 31-52, 1991.

[3] J. Brancheau, and J. Wetherbe, The Adoption of Spreadsheet Software: Testing Innovation Diffusion Theory in the Context of End-User Computing. Information Systems Research, vol. 1 and 2, pp.115 - 143, 1990.

[4] J.P. Cannon, and C. Homburg, Buyer-supplier relationships and customer firm costs. Journal of Marketing, pp. $29-43$, January, 2001.

[5] S. Chong, and G. Pervan, Implementation Success of Internet-based Electronic Commerce for Small- and Medium-sized Enterprises in Singapore, In Proceedings, International Telecommunications Society Asia-Indian Ocean Regional Conference, Perth, Western Australia, 2001.

[6] R. Cooper, and R. Zmud, Information technology implementation research: A technological diffusion approach. Management Science, vol. 36, no. 2, pp.123 - 139, 1990.

[7] B. Corbitt, G. Behrendorf, and J. Brown-Parker, SMEs and Electronic Commerce, The Australian Institute of Management, vol. 14, pp. $204-222,1997$.

[8] P. Cragg, and M. King, Small-firm computing: motivators and inhibitors. MIS Quarterly, vol. 17, no. 1, pp.47-60, 1993.

[9] L.J. Cronbach, Coefficient alpha and internal structure of tests, Psychometrika, vol. 16, no. 3, pp. 297 - 334 , 1951.

[10] M. Crum, G. Premkumar, and K. Ramamurthy, An assessment of motor carrier adoption, use, and satisfaction with EC. Transportation Journal, pp.44 - 57, Summer, 1996.

[11] F. Damanpour, Organizational innovation: A meta-analysis of effects of determinants and moderators, Academy of Management Journal, vol. 34, no. 3, pp.555-590, 1991.

[12] E.M. Daniel, and D.J. Grimshaw, An exploratory comparison of electronic commerce adoption in large and small enterprises. Journal of Information Technology, vol. 17, no. 3, pp.133 - 147, 2002.

[13] D. Davis, Business Research for Decision Making, 4th Ed., Duxbery Press, USA, 1996, pp. 173.

[14] R.R. Dholakia, and Kshetri. Factors Impacting the Adoption of the Internet among SMEs. Small Business Economics, vol. 23, no. 4, pp.311 - 322, 2004.

[15] eMarketer, IT and E-Business in the Asia-Pacific Region, eMarketer, EMA1175619, January, 2005.

[16] Forrester Research (2005, January) US eCommerce Forecast: Online Retail Sales To Reach \$329 Billion By 2010, Forrester Research Inc. [Online] Available http://www.forrester.com/Research/Document/Excerpt/0,7211,37626,00.html

[17] H. Gatignon, and T. Robertson, Technology Diffusion: An Empirical Test of Competitive Effects, Journal of Marketing, vol. 53, no. 1, pp.35 - 49, 1989.

[18] R. Germain, C. Droge, and P. Daugherty, A Cost and Impact Typology of Logistics Technology and the Effect of its Adoption on Organisational Practice. Journal of Business Logistics, vol. 15, no. 2, pp.227 - 248, 1994.

[19] J., Gibbs, L., Kraemer, and J. Dedrick, Environment and Policy Factors Shaping Global E-commerce Diffusion: A Cross-Country Comparison, The Information Society, Special Issue, 2003.

[20] E. Grandon, and J.M. Pearson, Electronic commerce adoption: an empirical study of small and medium US businesses, Information \& Management, vol. 42, no. 1, pp.197 - 216, 2003

[21] E. Grandon, and J.M. Pearson, Strategic Value and Adoption of Electronic Commerce: An Empirical Study of Chilean Small and Medium Businesses, Journal of Global Information Technology Management, vol. 6, no. 3, pp. $22-43,2003$. 
[22] J.F. Hair, R.E. Anderson, R.L. Tatham, and W.C. Black, Multivariate Data Analysis with Readings. 5th Ed., Englewood Cliffs, NJ: Prentice-Hall, 1998.

[23] C. Iacovou, I. Benbasat, and A. Dexter, Electronic Data Interchange and small organisations: Adoption and impact of technology. MIS Quarterly, vol. 19, no. 4, pp.465 - 485, 1995.

[24] IDC Australia (2004, August) IDC Predicts Double Digit Growth of Asia/Pacific Internet Buyers from 2003 to 2008, IDC Australia, [Online] Available: http://www.idc.com.au/newsletters/idcpulse/detail.asp?intID=43.

[25] J., Kendall, L. Tung, K.H. Chua, C.H. Ng, and S. M. Tan, Receptivity of Singapore's SMEs to electronic commerce adoption. Journal of Strategic Information Systems, vol. 10, no. 3, pp. 223 - 242, 2001.

[26] W.J. Kettinger, National infrastructure diffusion and the U.S. information super highway, Information and Management, vol. 27, no. 6, pp. $357-368,1994$

[27] J. King, V. Gurbaxani, and Kraemer. The institutional factors in Information Technology innovation, Information Systems Research, vol. 5, no. 2, pp.139 - 169, 1994.

[28] T. Kwon, and R. Zmud, Unifying the fragmented models of Information System implementation, in Critical Issues in Information System Research, Boland, R. and Hirschheim, R. (eds.), John Wiley, New York, 1987.

[29] K. Lal, E-business and manufacturing sector: A study of small and medium-sized enterprises in India. Research Policy, vol. 31, no.7, pp.1199-1211, 2002.

[30] C. Lertwongsatien, and N. Wongpinunwatana, E-commerce adoption in Thailand: An empirical study of Small and Medium Enterprises (SMEs). Journal of Global Information Technology Management, vol. 6, no. 3, pp.67 83, 2003.

[31] B. Massetti, and R. Zmud, Measuring the extent of EDI usage in complex organisations: Strategies and illustrative examples, MIS Quarterly, vol. 20, no. 3, pp.603 - 640, 1996.

[32] P. McCole, and E. Ramsey, A Profile of Adopters and Non-adopters of eCommerce in SME Professional Service Firms, Australasian Marketing Journal, vol. 13, no. 1, pp.36-48, 2005.

[33] J., Mohr, R. Fisher, and J. Nevin, Collaborative communication in interfirm relationships: Moderating effects of integration and control, Journal of Marketing, vol. 60, pp.349 - 370, 1996.

[34] G., Moore, and J. Benbasat, Development of an instrument to measure the perceptions of adopting an Information Technology innovation, Information System Research, vol. 2, no. 3, pp.191 - 222, 1991.

[35] L.W. Neuman, Social research methods: Qualitative and Quantitative Approaches. 4th Edition, Allyn \& Bacon, U.S.A., 1999.

[36] NOIE (2000, November) Current State of Play, [Online] Available http://www.noie.gov.au/projects/framework/Progress/ie_stats/StateOfPlayNov2000/index.htm

[37] S. Nilakanta, and R. Scamell, The effect of information sources and communication channels on the diffusion of innovation in a data base development environment. Management Science, vol. 36, no. 1, pp.24 - 40, 1990.

[38] J. Nunnally, Psychometric Theory. New York, NY: McGraw-Hill, 1978.

[39] F. Payton, and M. Ginzberg, Interorganisational health care systems Implementations: An exploratory study of early Electronic Commerce initiatives, Health Care Management Review, vol. 26, no. 2, pp.20 - 32, 2001.

[40] G. Premkumar, and K. Ramamurthy, The role of interorganisational and organizational factors on the decision mode for adoption of interorganisational systems. Decision Sciences, vol. 26, no. 3, pp.303 - 336, 1995.

[41] G. Premkumar, and M. Roberts, Adoption of new Information Technologies in rural small businesses. Omega, The International Journal of Management Science, vol. 27, pp.467-484, 1999.

[42] G. Premkumar, K. Ramamurthy, and S. Nilakanta, Implementation of electronic data interchange, Journal of Management Information Systems, vol. 11, no. 2, pp.157 - 186, 1994.

[43] K. Ramamurthy, G. Premkumar, and M. Crum, Organisational and interorganisational determinants of EDI diffusion and organisational performance: A casual model, Journal of Organisational Computing and Electronic Commerce, vol. 9, no. 4, pp.253 - 285, 1999.

[44] S.S. Rao, G. Metts, and C.A.M. Monge, Electronic commerce development in small and medium sized enterprises, Business Process Management Journal, vol. 9, no. 1, pp.11 - 32, 2003.

[45] E.M. Rogers, Diffusion of Innovations. 4th Ed. The Free Press, New York, NY, 1995.

[46] Sensis (2003, May) e-Business Report: The Online Experience of Small and Medium Enterprises, Sensis, [Online] pp. 2 Available http://about.sensis.com.au/media/pdf/SBA-Archive/sba/tae/2005SepSensiseBusinessReport.pdf

[47] C. Soh, Q.Y. Mah, F.Y. Gan, D. Chew, and E. Reid, The use of the Internet for business: The experience of early adopters in Singapore. Internet Research, vol. 7, no. 3, pp. 217-228, 1997.

[48] R. Stockdale, and C. Standing, Benefits and barriers of electronic marketplace participation: an SME perspective. Journal of Enterprise Information Management, vol. 17, no. 4, pp.301 - 311, 2004.

[49] M. Tan, Creating the digital economy: perspectives from Singapore. In Proceedings. 11th International Bled Electronic Commerce Conference - Electronic Commerce in the Information Society. Bled, Slovenia, 1998.

[50] M. Tan, and T.S.H. Teo, Factors Influencing the Adoption of Internet Banking, Journal of the AIS, vol. 1, no. 5, pp. 1-42, 2000.

[51] L. Tornatzky, and K. Klein, Innovation characteristics and innovation adoption-implementation: A meta analysis of findings. IEEE Transactions on Engineering Management, vol. 29, no. 11, pp.28 - 45, 1982.

[52] B.A. Wagner, I. Fillis, and U. Johansson, E-business and e-supply strategy in small and medium sized businesses (SMEs), Supply Chain Management, vol. 8, no. 4, pp.343 - 354, 2003.

[53] K. Zhu, K. Kraemer, and S. Xu, E-Business adoption by European firms: A cross-country assessment of the facilitators and inhibitors. European Journal of Information Systems, vol. 12, no. 4, pp. 251-268, 2003. 